DOI: 10.5007/2175-7941.2012v29n2p289

\title{
MEDINDO A MASSA DE UM ÍMÃ DURANTE SUA QUEDA
}

\author{
Danilo Claro Zanardi \\ Diogo Soga \\ Mikiya Muramatsu \\ Instituto de Física - USP \\ São Paulo - SP
}

\section{Resumo}

Este artigo explora as possibilidades de usos de um experimento lúdico: um ímã em queda vertical no interior de um tubo metálico não ferromagnético. O forte impacto visual aliado à abrangência de fenomenos faz desse experimento uma ferramenta de alto valor didático. A física subjacente ao experimento é explorada de uma forma qualitativa e quantitativa. Os dados tomados no item ensaio são todos simples e passíveis de reprodução no Ensino Médio. Apesar de já conhecido entre divulgadores de ciência, sua vasta gama de conceitos físicos ainda não havia sido reunida com um propósito pedagógico. Por fim, o efeito visual que aguça de forma mais notória a curiosidade das crianças das séries básicas, recebe destaque no item "Um pouco mais de dinâmica - Princípio da Ação e Reação". Esse é o efeito que, pelo forte apelo visual, serviu como inspiração para a elaboração do artigo. Este impacto visual é obtido quando o ímã cai vagarosamente no interior do tubo e sua massa é medida antes mesmo que ele atinja o prato da balança.

\footnotetext{
Measuring the mass of a magnet during its downfall

* Recebido: abril de 2012.

Aceito: junho de 2012.
}

Cad. Bras. Ens. Fís., v. 29, n. 2: p. 289-312, ago. 2012. 
Palavras-chave: Ensino de física. Leis de Faraday e Lenz. Experimento de forte impacto visual.

\begin{abstract}
In this paper, we explore the possibilities of uses of a ludic experiment: a magnet falling inside a non-ferromagnetic vertical metal tube. The strong visual impact along with the range of phenomena makes this experiment a higher-educational value one. The Physics underlying the experiment is explored in a qualitative and quantitative way. The datataken in the essay topic are all simple and feasible for High School levels. Although well - known among popularizers of Science, its wide range of physical concepts had not yet been reunited with a pedagogical purpose. Finally, the visual effect which sharpens more notoriously the curiosity of children is highlighted in the topic: A little more about DynamicsPrinciple of Action and Reaction. This is the effect that, for having a strong visual appeal, acted as an inspiration for the article. This visual impact is attained when the magnet falls slowly and its mass is measured even before it reaches the scale pad.
\end{abstract}

Keywords: Physics teaching. Faraday and Lenz laws. Experiment with a strong visual impact.

\title{
I. Introdução
}

O conteúdo relativo às leis de Faraday e Lenz é, algumas vezes, tido entre os alunos como um assunto difícil dentro da Física ensinada no Ensino Médio. Por este motivo, este tema é, por vezes, deixado de lado pelo professor, que acaba priorizando outros assuntos da extensa programação curricular da disciplina de Física. A verdade é que o ensino destas leis não é, de maneira alguma, uma tarefa fácil. Este artigo tem o intuito de mostrar um experimento lúdico que, tal como muitas outras contribuições que já foram dadas neste sentido, como pode ser visto nos trabalhos de Laburú e Arruda (2004), Pimentel e Zumpano (2008), Paula e Vianna (2007) e Pimentel (1998), entre outros, possa também auxiliar o ensino deste assunto. As particularidades deste experimento que justificam sua divulgação entre os docentes da área são: o seu impacto visual, seu caráter contra intuitivo e suas inúmeras possibilidades didáticas. Silveira, Levin e Rizatto (2007) trazem 
uma explicação minuciosa do cálculo da velocidade terminal de queda do ímã no interior do tubo, explicitando inclusive o valor desta velocidade em função do número de ímãs grudados em série. No entanto, o incrível potencial deste experimento em uma sala de aula da escola básica é pouco explorado no artigo, o que motivou sua divulgação sob a perspectiva didática.

\section{I.1 Descrição do experimento}

No interior de um tubo de alumínio, na posição vertical (Fig. 1), são abandonados objetos sem imantação. Depois de abandonados, atingem rapidamente a outra extremidade do tubo. No entanto, quando se abandona um ímã no interior do mesmo, este leva um tempo muito superior, quando comparado com os outros objetos não magnéticos, para atingir a outra extremidade do tubo. Em Silveira, Levin e Rizatto (2007, p. 299), esse tempo é da ordem de quarenta vezes maior para objetos magnéticos em relação a objetos não magnéticos. Olhando por cima no interior do tubo vertical (Fig. 2), percebe-se um movimento como que em "câmara lenta", dando a impressão de que o ímã está "flutuando".

\section{I.2 Física envolvida}

Pode-se pensar no tubo como sendo formado por inúmeras espiras metálicas justapostas (SILVEIRA; LEVIN; RIZATTO, 2007, p. 297), associadas em série (Fig. 3). Durante a queda, toda vez que o ímã se aproxima da próxima espira, o fluxo de campo magnético que a atravessa aumenta (Fig. 4), o que induz, de acordo com a Lei de Faraday, uma força eletromotriz (f.e.m) na mesma. Por ser a espira

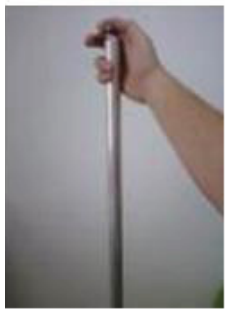

Fig. 1 - Tubo de alumínio colocado na vertical.

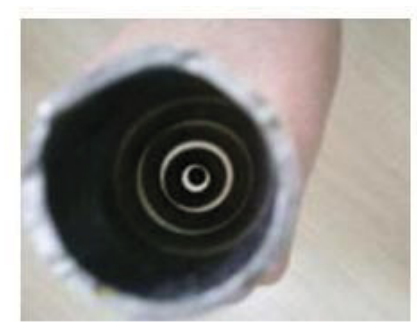

Fig. 2 - Ímã em formato esférico em queda vertical no interior do tubo de alumínio (fotografado de cima). metálica (alumínio), surge nela uma corrente elétrica. Essa corrente

\footnotetext{
1 Ver, por exemplo: Mago da Física - Freio Eletromagnético. Disponível em: $<$ http://www.youtube.com/watch?v=s5Jx8_905KY>.
} 
elétrica, por sua vez, gera outro campo magnético que, de acordo com a Lei de Lenz, tem sentido oposto à variação do campo magnético do ímã que atravessa a espira (Fig. 5).
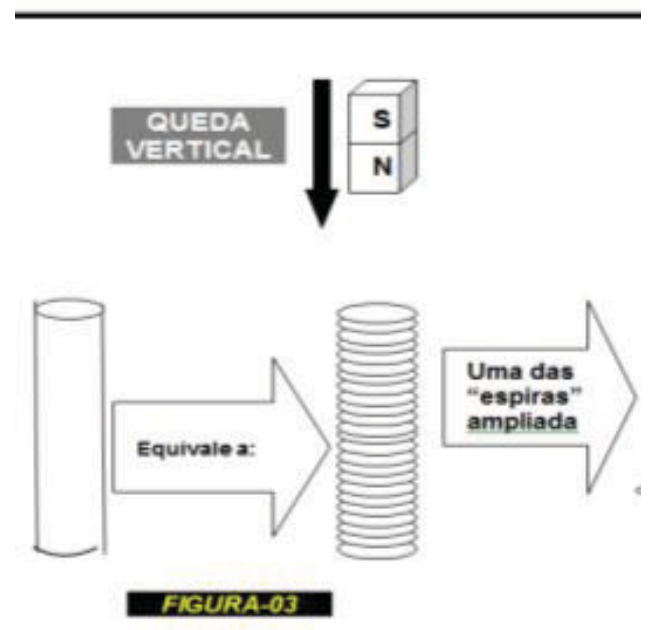

Fig. 3 - Pode-se pensar o tubo como sendo composto por infinitas espiras justapostas.

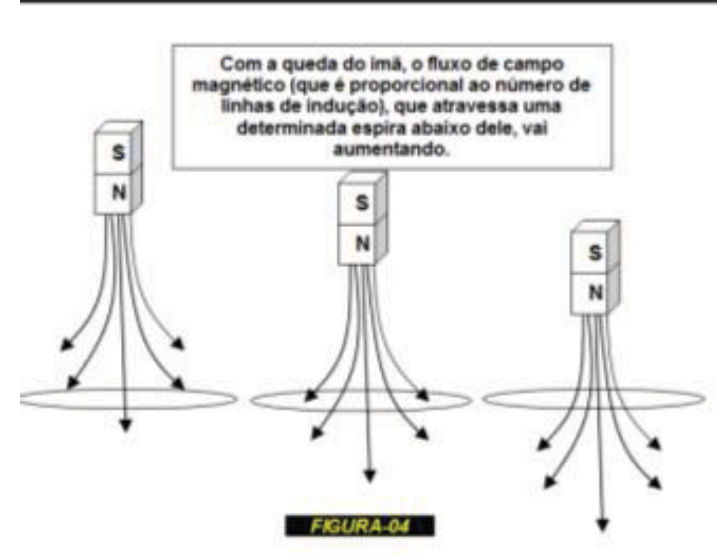

Fig. 4-Representação das linhas de indução do imã em queda que atravessa uma dessas espiras fictícias. 


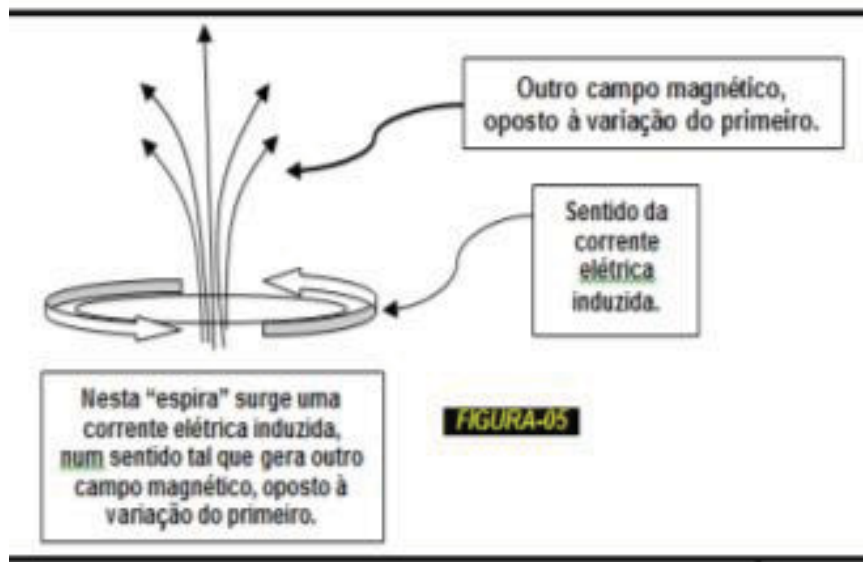

Fig. 5 - A espira da Fig. 4 passa, então, a ser percorrida por uma corrente elétrica induzida que gera outro campo magnético.

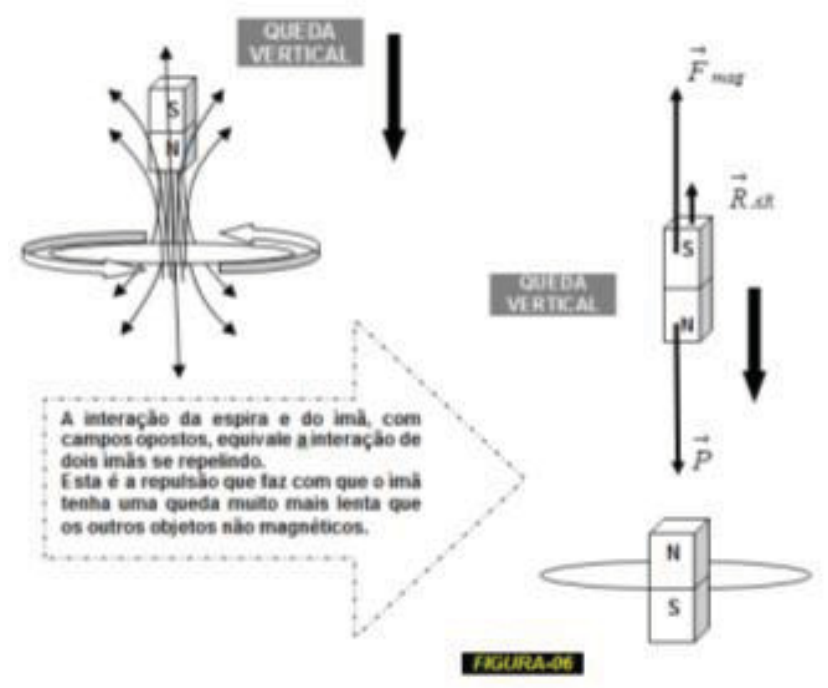

Fig. 6 - A interação entre o ímã e a espira é análoga à interação de dois ímãs que se repelem.

Cad. Bras. Ens. Fís., v. 29, n. 2: p. 289-312, ago. 2012. 
Como consequência, o primeiro campo magnético (do ímã) e aquele gerado pela corrente induzida na espira terão sentidos opostos. A espira passa a "funcionar" como outro ímã. A interação da espira com o ímã em queda, mediada pelos seus campos magnéticos, é equivalente à interação entre dois ímãs que estão com seus polos iguais (norte-norte ou sul-sul) voltados um contra o outro. Dessa maneira, a força magnética que cada uma das inúmeras espiras que compõem o tubo metálico provocará no ímã em queda, será de repulsão (Fig.6), com sentido oposto ao seu peso. Essa força é capaz de frear a queda rapidamente e fazer com que o ímã caia em um movimento retilíneo uniforme de baixa velocidade, sendo que o tempo para atravessar o tubo é muito superior ao tempo que gastam outros objetos não magnéticos.

\section{I.3 Montagem do experimento}

\section{Materiais}

- Um tubo de alumínio ou outro metal não ferromagnético, sendo que quanto mais espessa a parede do tubo, tanto melhor.

- O ímã pode ter um formato qualquer, contanto que apresente duas características: seja um ímã forte como são os ímãs de terras raras (por exemplo, de neodímio-ferro-boro), e que tenha dimensões suficientes para passar pelo tubo. Vale ressaltar que o ímã de formato esférico apresentou um efeito de "flutuação" mais notável que ímãs cilíndricos de mesmo diâmetro.

- uma balança com precisão de décimos de grama, de preferência uma balança digital para facilitar a leitura.

\section{Comentários}

a) Por simplicidade, foi desenhado e explicado apenas o que ocorre quando o ímã se aproxima da espira, apesar de que o mesmo raciocínio vale quando ele se afasta da espira.

b) Na prática, durante sua queda, o ímã gira, fazendo com que seu padrão de linhas de campo rotacione durante a queda. No entanto, a lei de Lenz garante que, esteja no sentido em que estiver, a variação do fluxo do campo magnético irá induzir uma corrente que gera outro campo magnético que se opõe à variação do primeiro, assegurando que a força magnética sobre o ímã seja sempre contrária à força da gravidade. Esse giro do ímã faz com que as correntes induzidas não sejam todas transversais aos tubos, mas em inúmeras direções inclinadas em relação ao eixo do tubo. Isso explica o fato de que, ainda que o tubo seja cortado na direção de seu comprimento em duas metades tipo canaletas, ainda assim o ímã 
abandonado na canaleta cairá vagarosamente ${ }^{2}$. Isso também explica o fato de o ímã não encostar-se às paredes internas do tubo, pois toda vez que tenta se aproximar destas, uma força repulsiva o move novamente para o eixo central do tubo, conforme explicado em Silveira, Levin e Rizatto (2007, p. 298).

c) Não existe nenhuma especificação precisa para os diâmetros dos tubos e dos ímãs, por tentativa e erro pode-se chegar a combinações que tenham efeitos cada vez mais notáveis. No caso particular de ímãs cilíndricos, Silveira, Levin e Rizatto (2007) mostraram que o efeito mais acentuado de frenagem ocorre quando a altura do ímã (ou associação de ímãs) tiver o mesmo valor do diâmetro da base circular, ou, o que é análogo, quando o ímã cilíndrico tiver uma seção, paralela ao eixo do cilindro, quadrada. Outra recomendação importante é que o diâmetro do ímã seja somente um pouco menor do que o diâmetro interno do tubo; quanto mais próximos esses valores, mais acentuado o efeito de frenagem.

d) O ímã de formato esférico, também com seu diâmetro quase igual ao diâmetro interno do tubo, apresenta um movimento bastante lento no interior do mesmo.

\section{Possibilidades didáticas}

O artigo de Silveira, Levin e Rizatto (2007), que inspirou a elaboração deste trabalho, apresenta um detalhamento da física envolvida neste experimento, assim como uma dedução da velocidade terminal do ímã em queda em função do número de ímãs que se associam em série.

$\mathrm{O}$ artigo presente, por outro lado, tem por intuito apresentar possibilidades didáticas relativas aos conceitos envolvidos, sem se aprofundar na tomada de dados propriamente dita, tampouco em uma formulação matemática mais profunda, tal como foi feito pelos autores citados acima. Nesse sentido, propõe-se o uso do experimento com um viés mais demonstrativo do que investigativo. Não obstante, sugere-se uma demonstração do tipo aberta, como aquela descrita por Araújo e Abib (2003), ou seja, com indagação sobre a física envolvida, sobre conceitos já aprendidos, perguntas provocadoras, levantamento de hipóteses, etc. Destaca-se, por fim, uma possibilidade inédita relacionada a este experimento e ainda não explorada em outros artigos de divulgação: a observação dos efeitos do Princípio de Ação e Reação, assim como o uso deste efeito para medir a massa do ímã en-

\footnotetext{
${ }^{2}$ Neste caso, porém, a canaleta deve ser mantida ligeiramente inclinada em relação à vertical; caso contrário, o ímã "escapa" da caneleta.
} 
quanto ele está caindo dentro do tubo, ou seja, a possibilidade de se medir sua massa durante sua queda, antes que o ímã toque no prato da balança.

A seguir, descrevem-se os conceitos que podem ser explorados com o uso deste experimento em sala de aula. A física relativa aos tópicos 2.1 a 2.4 é abordada em nível superior nas graduações de física ou engenharia e pode ser consultada em obras conhecidas como Hewitt (2009) e Halliday, Resnick e Walker (2001). O que se faz abaixo é relacionar esses conceitos com o experimento em questão, fornecendo elementos teóricos para que o professor, em sala de aula, sinta-se mais seguro em conduzir um diálogo com o aluno durante o uso do experimento.

\section{II.1 Lei de Faraday e Lei de Lenz}

No item "Física Envolvida" estão descritos os conceitos relacionados ao aparecimento da força magnética que freia o ímã. Por ser esta uma força magnética que, no caso deste experimento, se opõe à velocidade de queda do ímã, pode-se dizer que, nesse caso, trata-se de uma força magnética resistiva, especificação também atribuída por Silveira, Levin e Rizatto (2007, p.298). Essa força surge devido ao aparecimento do campo magnético secundário, gerado pela corrente elétrica induzida em cada uma das fictícias espiras que compõem o tubo metálico. Essa corrente elétrica induzida, por sua vez, depende da força eletromotriz induzida $\boldsymbol{\varepsilon}_{\text {ind }}$ e da resistência elétrica de cada uma dessas espiras, sendo diretamente proporcional à primeira e inversamente proporcional à segunda. Já a resistência elétrica dessas espiras aumenta com a resistividade elétrica do material que compõe o tubo (no caso do ensaio que foi feito, o alumínio), além de depender dos elementos geométricos dessas espiras, especialmente da espessura da parede do tubo. A força eletromotriz induzida $-\boldsymbol{\varepsilon}_{\text {ind }}-$, por sua vez, cresce com o aumento da variação de fluxo do campo magnético do ímã que atravessa a espira. Essa variação, finalmente, aumenta com o aumento da intensidade do campo magnético do ímã e com a velocidade com que o ímã passa pelo tubo. Os cálculos relacionados a todos esses parâmetros talvez sejam demasiadamente complexos para que sejam abordados de uma forma rigorosa no Ensino Médio e estão todos eles exaustivamente descritos e demonstrados no artigo de Silveira, Levin e Rizatto (2007). No entanto, a abordagem qualitativa desses parâmetros é perfeitamente plausível nessas séries, uma vez que todas essas leis e todos esses conceitos pertencem ao currículo de física do Ensino Médio. É importante que o aluno disponha, a menos a nível intuitivo, a noção de que:

- quanto mais forte o ímã, ou seja, quanto mais magnetizado ele for, mais intenso será seu campo magnético que atravessa as "espiras" do tubo; 
- quanto mais intenso este campo, maior o fluxo magnético (número de linhas de indução) que atravessa cada espira;

- quanto maior o fluxo que chega à próxima "espira", maior a variação de fluxo nesta espira, supondo uma mesma velocidade de queda;

- quanto maior a variação de fluxo no mesmo intervalo de tempo, maior a força eletromotriz induzida;

- quanto maior a força eletromotriz induzida, maior a corrente induzida, supondo constantes outros fatores;

- quanto maior a corrente induzida, maior o campo magnético secundário gerado por ela;

- quanto maior este campo magnético secundário, maior será a intensidade da força magnética (resistiva) que freia o ímã;

- quanto maior esta força resistiva, maior será o efeito de frenagem ("flutuação") do ímã.

Portanto, com o uso de ímãs de terras raras, que, por apresentarem intensa magnetização, têm campos magnéticos de alta intensidade, veremos melhor o efeito de "flutuação".

Quanto à resistividade do material:

- quanto menor a resistividade do condutor ou mais espessa a parede do tubo, menor será também a resistência elétrica de cada espira;

- quanto menor a resistência de cada espira, maior será a corrente induzida que nela pode se estabelecer (para uma mesma força eletromotriz induzida);

- e, como já se viu, quanto maior a corrente elétrica, maior o efeito de "flutuação" do ímã.

Enfim, quanto "mais condutor" for o material e mais forte for o ímã, mais notável será o efeito de "flutuação" do ímã em queda.

Outro aspecto a ser observado e que, de maneira geral, não é um assunto tratado em profundidade no Ensino Médio, é a caracterização do material do tubo quanto às suas propriedades magnéticas. Depois da apresentação desse experimento inúmeras vezes, constatou-se uma tendência dos alunos em acreditar que o tubo era feito de ferro, pois os alunos costumam ter consciência do fato de ímãs atraírem e ser atraídos por objetos de ferro. Acreditam, ingenuamente, que é justamente essa atração entre ímã e ferro que daria conta de explicar o fato do ímã apresentar uma queda lenta no interior do tubo. Não conhecem a diferença entre metais ferromagnéticos, paramagnéticos e diamagnéticos; respondem quase sempre acertadamente quando questionados sobre o que ocorreria caso o tubo fosse de madeira ou plásti- 
co, em vez de metálico. Quase nunca sabem dizer, no entanto, a diferença que seria observada caso o ímã fosse abandonado no interior de um tubo de ferro em vez de um metal não ferromagnético e não preveem que o fenômeno de queda lenta não ocorreria, uma vez que o ímã grudaria quase que instantaneamente na parede interna do tubo de ferro e cessaria sua queda.

\section{II.2 Cinemática e Dinâmica envolvida}

A velocidade terminal do ímã no interior do tubo é atingida rapidamente. Conforme pode ser visto em Silveira e Varriale (2009), uma vez que a força magnética resistiva é proporcional à velocidade de queda do ímã e a força motora é constante (no caso do ímã em queda vertical no interior do tubo, a força motora é a própria força da gravidade), essa velocidade irá apresentar um crescimento exponencial com o tempo. Os autores mostram, ainda, que o intervalo de tempo necessário para que o ímã atinja aproximadamente $63 \%(1-1 /$ e) de sua velocidade terminal, chamado de constante de tempo $(\tau)$, pode ser estimado dividindo-se o valor da velocidade terminal pelo valor da aceleração inicial do movimento, no caso, a aceleração da gravidade.

Desse modo, para o ensaio feito (ver dados na sequencia desta mesma seção), esse valor tem ordem de grandeza de $=\frac{10^{-1} \mathrm{~m} / \mathrm{s}}{10 \mathrm{~m} / \mathrm{s}^{2}}=10^{-2}=0,01 \mathrm{~s}$. De fato, esse intervalo de tempo tem ordem de grandeza muito menor que a ordem de grandeza do intervalo de tempo médio de queda do ímã que, conforme poderá ser visto nos dados a seguir, foi de 4,5 segundos.

A velocidade terminal, conforme descrito no item anterior, depende de fatores tais como a geometria do tubo, da intensidade do campo magnético gerado pelo ímã, assim como da resistividade elétrica do material que constitui o tubo metálico.

No raciocínio que será descrito a seguir, é fundamental que se tenha em mente dois conceitos:

i) Primeiramente, conforme explicado, a força magnética resistiva será tanto maior quanto maior for a velocidade do ímã (uma vez que velocidade maior implica maior taxa temporal de variação do fluxo do campo magnético através das espiras que compõem o tubo).

ii) Em segundo lugar, quanto maior a velocidade, menor o tempo que o ímã levará para atingir a extremidade do tubo.

Supondo desprezível a resistência do ar e, ainda, que todos os outros parâmetros sejam constantes, pode-se pensar apenas no que ocorre quando se varia a 
massa do ímã em queda no interior do tubo. No exato momento em que o ímã é abandonado, sua velocidade é nula e, consequentemente, é nula também a força magnética resistiva. Conforme ele começa a acelerar e sua velocidade vai aumentando, cresce também a força magnética resistiva (i). Sua velocidade, e consequentemente a força magnética resistiva que nele é exercida, irão crescer até o ponto em que essa força tenha intensidade igual à intensidade da força peso que puxa o ímã para baixo. Nesse instante, a força resultante no ímã passa a ser nula e, desse ponto em diante, ele passa a executar um movimento retilíneo uniforme, ou seja, atinge sua velocidade terminal. Note que, caso a massa do ímã fosse maior (mantido todo o resto constante), ele teria que atingir uma velocidade também maior para que a força magnética resistiva crescesse o suficiente e cancelasse sua "nova" força peso que, por suposição, agora é maior. Percebe-se, portanto, que, quanto maior for a massa do ímã, mais tempo levará para atingir a sua velocidade terminal e passará, assim, mais tempo acelerando e, desse modo, atingirá velocidades maiores e, consequentemente, atingirá a extremidade do tubo mais rapidamente, em tempos menores (ii). Seguir esse raciocínio pode levar a crer que esse processo - aumento da velocidade e da força magnética resistiva até que a força peso seja cancelada aconteça em um percurso quase integral do tubo metálico, mas esse não é o caso. Tudo isso ocorre, conforme foi estimado acima, em um tempo muito inferior àquele necessário para que o ímã atravesse integralmente o tubo ${ }^{3}$, de tal modo que um observador menos atento diria que o ímã teve uma queda uniforme todo o tempo, o que também não é verdade. Em outras palavras, esse processo de acelerar até atingir a velocidade terminal e iniciar uma queda uniforme ocorre nos primeiros instantes de queda (aproximadamente $0,01 \mathrm{~s}$ para o caso do nosso ensaio), e a maior parte da queda (aproximadamente 4,5 s para o caso do nosso ensaio) se passa com o ímã caindo com uma velocidade constante.

O raciocínio exposto considera ser possível o aumento da massa do ímã sem o respectivo aumento do seu momento de dipolo magnético. No entanto, aumentar a massa do ímã pode fazer com que o respectivo momento de dipolo também aumente. Uma intensidade maior do campo magnético do ímã faz com que a força magnética resistiva também seja maior, o que implicaria valores menores para a velocidade terminal do ímã. Observa-se, portanto, que essas duas variáveis, massa e momento de dipolo magnético, influenciam o valor da velocidade terminal do ímã. De acordo com o trabalho de Silveira, Levin e Rizatto (2007, p.299), os

\footnotetext{
3 O tempo necessário para que o ímã atinja sua velocidade terminal depende das características elétricas e magnéticas do ímã e do tubo. Fixando-se essas características, quanto mais longo for o tubo, maior será o percurso que o ímã realiza em movimento uniforme.
} 
modelos quantitativos dispostos na literatura, que tratam de momentos de dipolos magnéticos pontuais, preveem um decréscimo monotônico da velocidade terminal com o aumento da massa e respectivo aumento do momento de dipolo magnético. Os autores do trabalho citado acima realizam experimentos associando ímãs iguais em série e mostram que, diferentemente do que prevê a literatura, levando-se em conta a extensão dos ímãs associados em série, a velocidade terminal não apresenta um decréscimo monotônico com o amento da massa e do momento de dipolo magnético do ímã; ao contrário, existe um número 'n' "ótimo" de ímãs que devem ser associados em série para que a velocidade terminal seja mínima.

Então, por que a resistência do ar pode ser desprezada? De forma geral, corpos pequenos e densos são menos influenciados pela força de resistência do ar do que aqueles que apresentam maior tamanho e menor densidade (HEWITT, 2009 , p. 77 e p. 78 ). Esse é um raciocínio simples de entender se recordarmos que a resistência do ar é proporcional à área da seção transversal do objeto, enquanto seu peso é proporcional à sua massa. Pensando qualitativamente, podemos comparar dois objetos esféricos e maciços abandonados do repouso num local onde existe resistência do ar. Suponha, ainda, que ambos possuem a mesma massa $\boldsymbol{m}$, mas que um deles possui o tamanho e, portanto, a área $\boldsymbol{A}$, bem maior que o tamanho e área do outro objeto. Uma vez que possuem a mesma massa, serão puxados para baixo por forças pesos de mesma intensidade. No entanto, aquele que tem maior área sofrerá mais colisões com moléculas de ar durante sua queda e, assim, sofrerá uma maior influência da força de resistência do ar, o que irá desacelerar a queda mais bruscamente do que aquele que possui área menor. Para finalizar o raciocínio, basta perceber que o objeto de área e tamanho menor (mas de mesma massa $\boldsymbol{m}$ ), é mais denso do que seu par. Dessa forma, conclui-se que, de forma geral, para objetos que guardam as mesmas características geométricas, quanto maior a densidade, menor será o efeito resistivo da força de resistência do ar. Os ímãs utilizados no experimento possuem a característica de serem pequenos, maciços e densos. Tratase, portanto, de um caso no qual a força de resistência do ar tem intensidade desprezível, quando comparada à intensidade da força peso. Apesar do raciocínio qualitativo apresentado, faremos abaixo uma estimativa da ordem de grandeza (O.G.) do módulo da força de resistência do ar, comparando-a com a ordem de grandeza do módulo da força peso, para o ímã que foi utilizado no ensaio desse experimento.

Para superestimar a força de resistência do ar, usaremos sua fórmula para altas velocidades: $R_{a r}=\frac{1}{2} \cdot \mathrm{C} \cdot \rho \cdot \mathrm{A} \cdot V^{2}$ (HALLIDAY; RESNICK; WALKER, 2001, p. 104), que resulta em valores maiores do que aqueles obtidos para baixas veloci- 
dades. Com isso, quer-se mostrar que, ainda que superestimada, a força de resistência do ar será muito menor que a força peso para o experimento em questão e, portanto, pode ser desprezada. Os dados abaixo são valores aproximados para fins de estimativa de ordem de grandeza.

\section{Dados:}

- Diâmetro do ímã: $\mathrm{D}=1,9 \mathrm{~cm}$

- Área de seção transversal: $\mathrm{A}=2,8 \cdot 10^{-4} \mathrm{~m}^{2}$

- Massa do ímã: $\mathrm{m}=27 \mathrm{~g}=2,7 \cdot 10^{-3} \mathrm{~kg}$

- Densidade do ar: $\rho=1,2 \mathrm{~kg} / \mathrm{m}^{3}$

- Aceleração da gravidade: $\mathrm{g}=10 \mathrm{~m} / \mathrm{s}^{2}$

- Coeficiente de arrasto aerodinâmico: $\mathrm{C}=1,0$ (tabela digital)

- Comprimento do tubo: $50,2 \mathrm{~cm}$

- Tempo médio de queda do ímã no interior do tubo: 4,5 s

Assim, tem-se:

$\mathrm{V}=11 \mathrm{~cm} / \mathrm{s}=0,11 \mathrm{~m} / \mathrm{s}=1,1 \cdot 10^{-1} \mathrm{~m} / \mathrm{s}$

$\mathrm{P}=\mathrm{m} \cdot \mathrm{g}=27 \cdot 10^{-3} \cdot 10=0,27$ newtons $=2,7 \cdot 10^{-1} \mathrm{~N} \Rightarrow$ Ordem de Grandeza (O.G.) $=10^{-1}$

$R_{a r}=\frac{1}{2} \cdot \mathrm{C} \cdot \rho \cdot \mathrm{A} \cdot V^{2}=\frac{1}{2} \cdot 1,0 \cdot 1,2 \cdot 2,8 \cdot 10^{-4} \cdot\left(1,1.10^{-1}\right)^{2}=2 \cdot 10^{-6}$ newtons $\Rightarrow$ O.G. $=10^{-6}$

Portanto, tem-se que:

$\frac{O . G \cdot P E S O}{O \cdot G \cdot \text { resistência do ar }}=\frac{10^{-1}}{10^{-6}}=10^{5}$

Ou seja, nesse caso, o módulo da força peso tem ordem de grandeza cem mil vezes maior do que a estimativa do módulo da força de resistência do ar, o que justifica com segurança o desprezo da segunda força, quando em presença da primeira.

Outra força presente no ímã durante sua queda é a força empuxo, advinda do fato de o ímã estar imerso no fluido ar. No entanto, essa força foi desconsiderada por ter intensidade desprezível em relação às intensidades das outras forças presentes. 


\section{II.3 Um pouco mais de dinâmica: Princípio da Ação e Reação}

No tópico acima, descrevemos as forças que são exercidas no ímã durante sua queda: força peso, força magnética resistiva e força de resistência do ar. Pensaremos, agora, sobre as forças que são exercidas no tubo de alumínio durante a queda do ímã em seu interior. Caso o tubo, durante a queda do ímã, esteja sendo segurado por alguém, tal como ilustrado na Fig. 1, pode-se pensar que nele (tubo) são exercidas duas forças: a força peso e a força de contato que a mão da pessoa exerce nele, sendo que essa última o sustenta na vertical. No entanto, um olhar mais atento revelará uma terceira força no tubo enquanto o ímã estiver em queda em seu interior. Para entender essa terceira força, temos que recordar as forças no ímã: a força peso no ímã é exercida pelo planeta Terra; a força de resistência do ar surge devido às colisões da superfície do ímã com as moléculas de ar abaixo dele. Mas, quem é o agente responsável por exercer a força magnética resistiva no ímã? Vimos que essa força surge da interação entre o ímã e o tubo que, por ser percorrido por corrente elétrica induzida, possui cargas elétricas em movimento. Assim, quem causa a força magnética resistiva no ímã é o próprio tubo metálico, mais precisamente, a força existe graças ao campo magnético gerado por essas cargas elétricas que estão em movimento nas paredes do tubo.

Caso seja necessário se aprofundar na questão, basta lembrar que, no referencial do tubo ou das espiras que o constituem, existe a variação do campo magnético do ímã se aproximando, o que, pela lei de Faraday, causa o aparecimento de um campo elétrico nas espiras do tubo, campo este que acelera os elétrons livres da espira, dando origem à corrente elétrica induzida na mesma. Essa corrente elétrica, por sua vez, gera o campo magnético secundário que se opõe ao campo do ímã. $\mathrm{O}$ ímã, agora, fica imerso no campo da espira. Os elétrons do próprio ímã, que geram o seu campo, ficam, então, sujeitos a uma força devido ao fato de estarem imersos no campo magnético secundário gerado pelas espiras.

A situação é a mesma exemplificada em Halliday, Resnick e Walker (2001, p. 751, fig. 32-8), que foi reproduzida abaixo para representar as características do nosso experimento.

Note que a situação é simétrica:

- Elétrons em movimento no ímã geram um campo magnético $(\vec{B} i ́ m \tilde{a})$;

- elétrons em movimento nas espiras do tubo geram um campo magnético ( $\vec{B}$ das espiras);

- elétrons do ímã, por estarem imersos no campo magnético gerado pelas espiras ( $\vec{B}$ das espira) e apresentarem velocidades não alinhadas com este campo, 
ficam sujeitos a uma força infinitesimal $(\overrightarrow{d F}$ no imã $)$. A resultante de todas essas forças nos elétrons do ímã é a força magnética (resistiva) ascendente que freia a queda do ímã;

- elétrons do tubo, por estarem imersos no campo magnético gerado pelo ímã ( $\vec{B} i ́ m \tilde{a})$ e apresentarem velocidades não alinhadas com esse campo, ficam sujeitos a uma força infinitesimal ( $\overrightarrow{d F}$ nas espiras do tubo). A resultante de todas essas forças nos elétrons do tubo é a força magnética descendente que "força" o tubo para baixo e comprime o prato da balança durante a queda do ímã.

A condição de não alinhamento entre a velocidade do elétron livre e o vetor indução magnética se deve ao fato de essa força ter sua intensidade calculada como o produto vetorial do vetor velocidade $\vec{V}$ da carga elétrica imersa no campo, com o vetor indução magnética $\vec{B}$ desse campo:

$$
F_{m a g}=q \vec{V} \times \vec{B}=q V B \operatorname{sen} \theta,
$$

onde $\theta$ é o ângulo entre o vetor velocidade $\vec{V}$ e o vetor indução magnética $\vec{B}$. No caso em que esses vetores estão alinhados, a força se anula, pois $\operatorname{sen} 0^{\circ}=$ $\operatorname{sen} 180^{\circ}=0$.

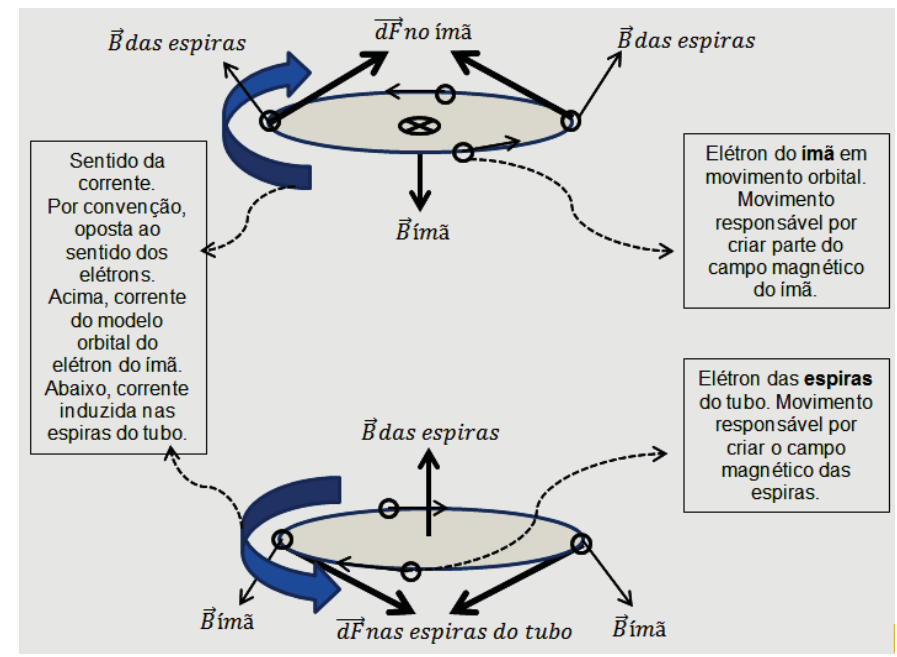

Fig. 7 - Esquema que representa uma visão microscópica de um elétron em movimento orbital de um átomo do ímã em queda, assim como um elétron em movimento por uma das espiras que compõem o tubo. 
A discussão acima pode ser resumida, para efeitos didáticos, pela seguinte afirmação: o ímã exerce uma força magnética no tubo e o tubo exerce uma força magnética no ímã. Em outras palavras, essas forças, que são exercidas em corpos distintos (ímã e tubo) e possuem mesma natureza (magnética), constituem-se em um exemplo de par ação-reação, ou seja, obedecem à terceira lei de Newton.

$\mathrm{Se}$, à primeira vista, esse fato não parece ter muita relevância em termos didáticos, um olhar atento releva um potencial didático de alto impacto visual. Observe que, se a força magnética que o tubo exerce no ímã tem sentido ascendente, então, a força que este exerce no tubo, de acordo com o princípio de ação e reação, tem sentido descendente. Em termos práticos, enquanto em queda, o ímã ficará exercendo uma força vertical para baixo no tubo. Recordando que ação e reação possuem o mesmo módulo e recordando ainda que, como discutido no tópico cinemática e dinâmica envolvida, a força magnética resistiva no ímã em queda em movimento retilíneo uniforme tem mesmo módulo que sua força peso (desprezando-se a resistência do ar), conclui-se, então, que a força que o ímã em queda exerce no tubo para baixo também tem o mesmo módulo da força peso no ímã. Colocando de uma maneira mais simples: enquanto cai, o ímã exerce no tubo uma força para baixo que tem o mesmo módulo de sua força peso. Isso quer dizer que a pessoa que estiver sustentando o tubo no ar enquanto o ímã estiver caindo terá que exercer no tubo uma força cujo módulo é equivalente ao peso do tubo mais o peso do ímã.

Finalmente, chega-se ao ponto almejado: se, em vez de uma pessoa segurando o tubo na vertical, este estiver apoiado sobre uma balança, então, a força que estará comprimindo a balança, enquanto o ímã estiver em queda, terá o valor somado do peso do tubo com o peso do ímã. Aquele que estiver observando o registro da balança enquanto o ímã estiver caindo, observará que a mesma indica não apenas a massa do tubo, mas também a massa do ímã. O surpreendente do experimento e o que causa um impacto visual considerável é que, durante a queda, o ímã não mantém contato nem com o tubo e nem com a balança, que, ainda assim, registra sua massa, ou seja, a massa do ímã é medida durante sua queda! Vale notar que, enquanto o ímã está sendo segurado em repouso na extremidade superior do tubo, ou seja, antes de ter sido abandonado, a balança registra apenas a massa do tubo metálico que está em repouso sobre ela. Porém, após soltar o ímã e o mesmo atingir a velocidade de queda constante, o que, como se viu nas seções anteriores, ocorre rapidamente, a balança passa a registrar um valor que equivale à massa do tubo mais a massa do ímã. É importante observar ainda que, depois de finda a queda, o ímã permanece parado sobre a balança e, portanto, a mesma continua registrando o mesmo valor que registrava durante a queda do ímã (após ele ter 
atingido sua velocidade terminal). Outro detalhe importante que não se pode omitir é que, nos milissegundos finais de queda, momento do ímã atingindo o prato da balança, nesse pequeno intervalo de tempo, a força que o prato da balança exerce no ímã, para cima, tem módulo maior que o peso do mesmo, uma vez que essa força tem de frear o ímã até que ele chegue ao repouso. Esse aumento temporário confere um acréscimo à indicação da balança. No entanto, esse processo é suficientemente rápido para que o registro desse pico e o retorno ao equilíbrio sequer possam ser observados a olho nu no display da balança.

\section{II.4 Conservação de energia}

Outra possibilidade didática desse experimento lúdico é a abordagem do princípio de conservação de energia. Faremos uma discussão, desprezando-se a resistência do ar que, como se viu, tem intensidade muito pequena, quando comparada à intensidade da força peso.

Como é bem sabido, se o ímã estivesse em queda livre, ganharia energia cinética ao longo de toda a queda. Nesse caso, a força peso seria a única força exercida, sendo o seu trabalho idêntico à variação da energia cinética. No entanto, caindo no interior do tubo condutor, não é isso que ocorre, pois o ímã rapidamente atinge a velocidade terminal de queda e cessa o ganho de energia cinética, enquanto a sua energia potencial gravitacional continua diminuindo. Para onde, então, está indo a energia potencial gravitacional que o ímã está perdendo? Pelo princípio de conservação de energia, essa energia potencial gravitacional tem necessariamente de se transformar em outra modalidade de energia. Mas qual? Para responder a essa pergunta, basta notar que a força que impede a aceleração do ímã é a força magnética que surgiu devido ao movimento dos elétrons livres das espiras do tubo. Contudo, de onde vem a energia para que os elétrons livres do tubo se movimentem? A energia necessária para manter a corrente elétrica que circula no tubo é igual à perda de energia potencial gravitacional que o ímã apresenta quando se movimenta com velocidade constante; ou seja, para fazer circular uma corrente elétrica nas paredes do tubo, devido à resistência elétrica que o condutor apresenta, é necessário um dispêndio de energia que, nesse caso, resulta ser igual à perda de energia potencial gravitacional do ímã. Outra questão que poderia surgir neste ponto é a seguinte: por que há necessidade de se despender energia para fazer circular uma corrente elétrica no tubo? Os elétrons livres, ao iniciarem seu movimento ordenado em uma determinada direção, ou seja, ao estabelecerem uma corrente elétrica, colidem com os íons da rede metálica do material do tubo. Neste ponto, vale lembrar que os íons da rede, diferentemente dos elétrons livres, têm movimen- 
tos em torno de posições de equilíbrio. Esse movimento dos íons, de natureza oscilatória, é quem confere parte da energia térmica do tubo (a outra parte é dada pelo próprio movimento térmico e não ordenado dos elétrons livres). Voltando às colisões, ressalta-se que as colisões dos elétrons livres em movimento ordenado com os íons da rede metálica transferem energia para estes íons que, então, passam a ter movimento térmico mais intenso. Resumindo, a perda de energia potencial gravitacional do ímã que cai com velocidade constante determina um aumento da energia térmica da rede cristalina iônica que compõe o tubo, ou seja, esquenta o tubo! Esse efeito - da passagem da corrente elétrica aumentar a energia térmica do condutor por onde ela passa - é bastante conhecido em eletricidade e chamado de efeito Joule. Mais uma vez, poderia surgir uma pergunta: Mas, então, caso fiquemos jogando vários ímãs pelo tubo, incessantemente, durante horas, seríamos capaz de esquentá-lo a tal ponto que ele viesse a fundir? Para fundir as paredes do tubo, é necessária uma potência elétrica grande. Ora, a potência elétrica desenvolvida sobre o tubo é idêntica à potência desenvolvida pela força gravitacional no ímã que cai. É fácil estimar que tal potência é muito pequena (da ordem de alguns miliwatts apenas) para o ímã descendo com velocidade constante.

Por fim, vale observar uma última transformação de energia que, na verdade, é anterior às expostas acima. Poderia ser questionado de onde vem a energia potencial gravitacional que o ímã apresenta no início da sua queda. Para entender isso, basta que se observe que, para que o ímã seja abandonado da extremidade superior do tubo, alguém tem que levantá-lo até tal posição, retirando o ímã de uma posição mais baixa e elevando-o a uma posição superior. Para tanto, essa pessoa tem de fazer uma força sobre o ímã, de sentido ascendente, oposto ao peso do mesmo e ela, ao erguer o ímã, tem que gastar energia. É bem verdade que, em comparação ao gasto energético diário de um ser humano, essa quantia é praticamente insignificante, mas não é nula! Se a pessoa gastou energia para erguer o ímã, essa energia não pode ter simplesmente desaparecido: tem que ter sido transformada. E para onde foi essa quantidade de energia? Note que, ao erguer o ímã, a pessoa teve de exercer uma força maior do que a força gravitacional da região compreendida entre as posições inicial e final do ímã. Caso não existisse a força peso atuante no ímã, a força ascendente que essa pessoa exerce no ímã, ao realizar trabalho, aceleraria o mesmo. No entanto, a força peso também está presente e, ao realizar trabalho durante o levantamento do ímã, retira a energia que a pessoa está transferindo e a deposita na forma de energia potencial gravitacional, energia essa que fica armazenada no campo gravitacional. Observe que, ao ser erguido, a distância entre o ímã e o planeta Terra aumenta, o que acarreta em um acréscimo de 
energia potencial do sistema Terra-ímã. Desse ponto em diante, já discutimos anteriormente.

E de onde vem a energia que a pessoa gasta para erguer o ímã? Esta provém da energia bioquímica armazenada em suas células que, por sua vez, tem origem na energia do alimento que foi ingerido. Enfim, poderíamos dizer que, como resultado líquido, esse experimento tem a capacidade de transformar a energia, por exemplo, do chocolate ingerido, em calor lançado no ambiente!

E de onde vem a energia do alimento? Bom, daí a discussão teria que ir longe, literalmente ao Sol e às estrelas, mas foge do objetivo deste artigo!

\section{Ensaio}

Para que constasse um exemplo concreto, descrevemos e ilustramos abaixo um ensaio que fizemos desse experimento.

\begin{tabular}{|l|}
\hline \multicolumn{1}{|c|}{ TUBO E OUTROS MATERIAIS } \\
- material: alumínio \\
- comprimento: $(50,2 \pm 0,1) \mathrm{cm}$ \\
- diâmetro interno: $2,0 \mathrm{~cm}$ \\
- balança com precisão de décimos de \\
grama; \\
- as placas para sustentar o tubo e evi- \\
tar o ar-comprimido; \\
- um suporte rígido (para manter o ímã \\
afastado da balança o suficiente para \\
que o campo magnético não interfira \\
no registro da balança).
\end{tabular}

\begin{tabular}{l} 
ÍMÃ \\
- composição: Neodímio, Ferro e \\
Boro \\
- formato: esférico \\
- diâmetro: $1,9 \mathrm{~cm}$ \\
- ordem de grandeza da indução \\
magnética de ímãs de neodímio- \\
ferro-boro na face do ímã: entre \\
$10^{-1}$ T e $10^{0}$ T (SILVEIRA; LE- \\
VIN; RIZATTO, 2007, p. 299) \\
\hline
\end{tabular}

Observação: Nas Fig. 8, 9, 10 e 11, a balança está em tara para todos os componentes que estão sobre ela, exceto para o ímã.

\section{III.1 Descrição da montagem experimental}

Sobre o prato da balança, colocamos um suporte rígido (vide Fig. 8) de 12 $\mathrm{cm}$ de altura e, sobre este, posicionamos placas que sustentam o tubo na posição vertical e o mantêm afastado do topo do suporte, para que o ar arrastado pelo ímã dentro tubo não seja comprimido dentro do mesmo (vide Fig. 9). Além disso, o 
suporte rígido garante que o campo magnético do ímã não interfira nos componentes mecânicos e eletrônicos da balança. $\mathrm{O}$ tubo fica apoiado em equilíbrio. Abandona-se, então, o ímã dentro do tubo e registra-se o valor da massa indicada pela balança.

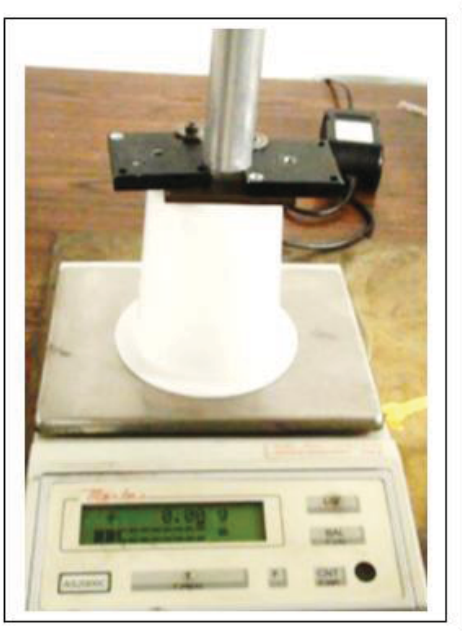

Fig. 8 - Valor médio para o registro da balança (em tara), antes do abandono do ímã:

$$
(0,0 \pm 0,1) \mathrm{g} \text {. }
$$

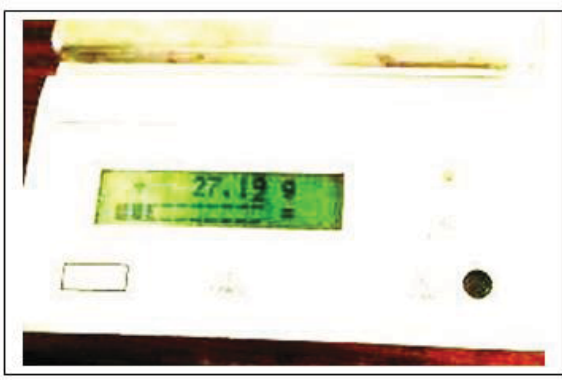

Fig. 10 - Valor médio para o registro da balança durante a queda do ímã:

$$
(27,2 \pm 0,1) \mathrm{g} \text {. }
$$

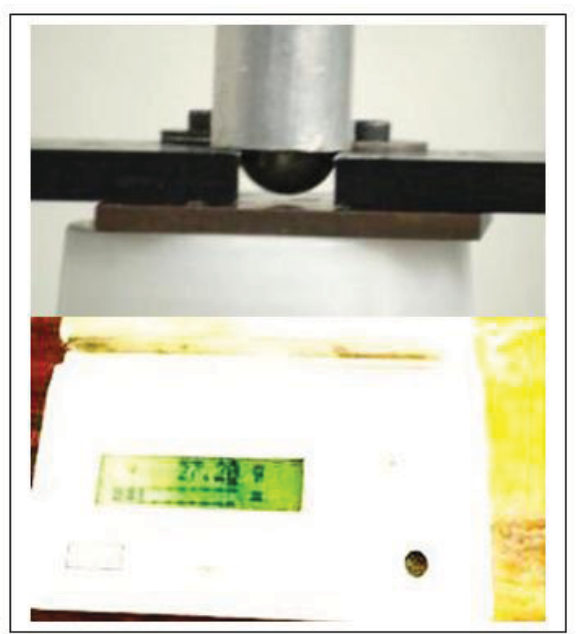

Fig. 9 - Valor médio para a medida da massa do ímã apoiado em repouso no prato da balança:

$$
(27,2 \pm 0,1) \mathrm{g} \text {. }
$$

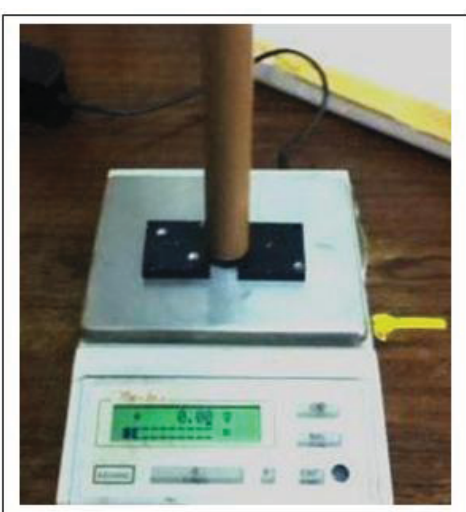

Fig. 11 - Valor médio para o registro da balança durante a queda do ímã em um tubo de PVC:

$$
(0,0 \pm 0,1) \mathrm{g} \text {. }
$$


A balança digital possui um recurso útil, a tara, que zera a leitura mesmo com objetos sobre ela. Assim, podemos visualizar no display apenas a massa do ímã em queda.

O ímã é solto dentro do tubo e faz-se a leitura. Como o tubo tem comprimento suficiente, verifica-se que a massa registrada pela balança atinge um valor máximo rapidamente e permanece constante por alguns segundos. Após o ímã atingir o suporte (no final da queda), o valor no display da balança não muda, ou seja, é igual ao valor máximo registrado anteriormente durante a queda do ímã.

Quanto mais longo for o tubo, melhor a percepção de que o ímã está em queda uniforme e que a balança registra, de fato, a massa do ímã enquanto ele está caindo.

Uma variação interessante do experimento e que pode ser sugerida ao professor é que ele segure o tubo, ou peça a um aluno que o faça, de forma a impedir que o mesmo toque no prato da balança e mostrar que, neste caso, a balança irá registrar a massa do ímã apenas quando ele atingir o suporte no final da queda, e depois repetir o experimento original, deixando que o tubo fique apoiado sobre o suporte.

\section{Considerações finais}

Este experimento pode servir muito bem ao propósito motivacional do ensino dessas leis, dado seu caráter visual impactante. Por outro lado, o fechamento do assunto pode ser uma ocasião onde seu uso seja feito no sentido de recordar e unir inúmeros conceitos abordados durante o ensino de eletricidade e eletromagnetismo. Segue abaixo uma lista de perguntas que podem ser exploradas ao se conduzir o processo de ensino e aprendizagem do assunto eletricidade com o uso deste experimento:

01) Você percebe a diferença de queda desta "bolinha" em comparação à queda destes outros objetos?

02) Você sabe dizer qual ou quais dos parâmetros: velocidade, distância ou tempo, diferenciam a queda desta bolinha das quedas de outros objetos?

03) Você sabe dizer o que esta bolinha tem ou qual característica que apresenta que faz com que ela caia mais lentamente que os outros objetos?

04) Você sabe dizer se o material do qual o tubo é feito tem alguma influência neste movimento diferenciado da queda da bolinha? 
05) Você sabe dizer se num tubo de madeira ou plástico este efeito de "flutuação" seria observado?

06) Você sabe dizer se num tubo de ferro este efeito de "flutuação" seria observado?

07) Você saberia citar as leis que explicam o fato de o ímã apresentar uma queda lenta em relação aos objetos não magnéticos?

08) Você saberia dizer de que forma a intensidade do campo magnético do ímã influencia a lentidão de sua queda?

09) Você saberia dizer de que maneira ou quais as características do material que constitui o tubo influenciam no efeito observado?

10) Você saberia dizer de que maneira os aspectos geométricos do tubo influenciam no efeito observado?

11) Você saberia dizer quais são as forças que atuam no ímã durante sua queda?

12) Você seria capaz de desenhar os sentidos destas forças?

13) Você saberia dizer qual ou quais destas forças poderiam ser desprezadas por terem intensidades menores se comparadas às intensidades das demais?

14) Você saberia dizer a intensidade da força resultante enquanto o ímã está em queda retilinea e uniforme?

15) Você acredita que poderia ser afirmado que o movimento do ímã foi uniforme desde o instante de seu abandono?

16) Você saberia dizer quais são as forças que são exercidas no tubo durante a queda do ímã em seu interior?

17) Você seria capaz de desenhar o sentido das forças que são exercidas no tubo?

18) Você sabe dizer por que razão a balança alterou sua indicação depois que o imã foi abandonado?

19) Você seria capaz de identificar as transformações de energia durante a queda do ímã?

20) Você seria capaz de calcular a velocidade média do ímã durante sua queda?

21) Como explicar a possibilidade de se medir a massa do ímã durante sua queda? 
Para assistir ao filme do ímã em queda, acesse:

$<$ http://www.youtube.com/watch?v=VXVd8aK7gV0\&feature=youtu.be $>$.

\section{Referências}

ARAÚJO, M. S. T. D.; ABIB, M. L. V. D. S. Atividades experimentais no ensino de física: diferentes enfoques, diferentes finalidades. Revista Brasileira de Ensino de Física, São Paulo, v. 25, n. 2, 2003.

HALLIDAY, D.; RESNICK, R.; WALKER, J. Fundamentals of Physics. 6. ed. Editora Wiley, 2001.

HEWITT, P. G.; WOLF, P. R. Fundamentos de Física Conceitual. São Paulo: Bookman, 2009.

LABURÚ, C. E.; ARRUDA, S. M. A construção de uma bobina de tesla para uso em demonstrações na sala de aula. Caderno Brasileiro de Ensino de Física, v. 21, n. especial, p. 217-226, 2004.

PAULA, A. G.; VIANNA, D. M. Levitação eletrodinâmica: o ensino de física, baseado no enfoque CTS, na discussão para a melhoria da qualidade do ar. Física na Escola, São Paulo, v. 8, n. 1, p. 35-39, 2007.

PIMENTEL, J. R. A tesoura de Gauss: uma tesoura para cortar linhas de campo magnético. Caderno Catarinense de Ensino de Física, v. 15, n. 1, p. 82-86, 1998.

PIMENTEL, J. R.; ZUMPANO, V. H. Demonstre em aula: correntes de Foucault exploradas com um disco rígido de computador. Caderno Brasileiro de Ensino de Física, v. 25, n. 1, p. 160-167, 2008.

SILVEIRA, F. L.; LEVIN, Y; RIZZATO, F. B. A frenagem eletromagnética de um ímã que cai. Caderno Brasileiro de Ensino de Física, v. 24, n. 3, p. 295-318, 2007.

SILVEIRA, F. L.; VARRIALE, M. C. O rolamento do magneto na rampa: uma interessante aplicação da lei de Faraday-Lenz. Revista Brasileira de Ensino de Física, v. 31, n. 4, dez. 2009 
Tabela com valores de coeficientes de arrasto aerodinâmico:

Disponível em:

http://www.portalsaofrancisco.com.br/alfa/resistencia-do-ar/resistencia-do-ar.php. Acesso em: 28 dez. 2011. 